\title{
Minimal Invasive Surgery for Cholangiocarcinoma
}

\author{
Jai Young Cho ${ }^{1}$, Ho-Seong Han ${ }^{1}$, Young Rok $\mathrm{Choi}^{1}$, Yoo-Seok Yoon ${ }^{1}$, Woohyung Lee ${ }^{2}$
}

'Department of Surgery, Seoul National University Bundang Hospital, Seoul National University College of Medicine, Republic of Korea

2Department of Surgery, Gyeongsang National University Hospital, Republic of Korea

\section{ABSTRACT}

Intrahepatic cholangiocarcinoma (IHCC) is a common primary hepatic tumor. However, its outcomes are usually worse than those of hepatocellular carcinoma owing to its non-specific presentation and detection at an advanced stage. Surgery is the best treatment option that offers a chance of long-term survival. Minimal invasive procedures for IHCC were not well performed frequently due to necessity for major laparoscopic liver resection (LLR) with possible inclusion of caudate resection (for Klatskin tumor), laparoscopic lymphadenectomy, and laparoscopic biliary-enteric anastomosis. However, several reports showed comparable outcomes to conventional surgery, although, in small cases series studies.

Key words: hepatectomy, bile duct cancer, laparoscopy, lymphadenectomy

\section{INTRODUCTION}

Hepatobiliary surgery is technically demanding procedures and postoperative complication is relatively high. Furthermore, the application of laparoscopic procedure to hepato-biliary surgery is more demanding. However, the indication for laparoscopic resection has been expanded owing to accumulated experience in this filed and the development of useful instrument (1).

Laparoscopic liver resection (LLR) is already well propagated all over the world. Although performing laparoscopic major hepatectomy is limited to experienced center, laparoscopic left lateral sectionectomy is widely performed and considered as a standard procedure. The indication of LLR includes hepatocellular carcinoma and colorectal liver metastasis. However, LLR for intrahepatic cholangiocarcinoma (IHCC) is not yet well indicated. Resection for IHCC commonly includes extended hepatectomy (49-87\%) with extrahepatic biliary resection $(21-29 \%)$. Although, the role of node dissection in the treatment of IHCC is still controversial, recent guideline recommends node dissection for accurate staging during surgical procedures. However, several studies showed the rarity of node metastasis in peripheral small sized IHCC, which cast a doubt on the necessity of the node dissection. In addition, there are several studies, which showed similar oncologic outcome in patients who underwent limited resection without lymph node dissection compared with
Corresponding author: Ho-Seong Han, MD Department of Surgery Seoul National University Bundang Hospital, 300 Gumi-dong, Bundang-gu Seongnam-si, Gyeonggi-do, 463-707 Korea

Telephone: 82-31-787-7091

Fax: 82-31-787-4078

E-mail: hanhs@snubh.org 
extended resection. Therefore, we have to establish the role of lymph node dissection through the confirmative data. Several comparative studies on LLR versus open surgery for IHCC have been reported. They showed no significant differences in perioperative and oncologic outcomes between open and laparoscopic resection group. Furthermore, oncologic outcome was not different regardless of node dissection.

The management of hilar cholangiocarcinoma needs special considerations. Surgical treatment includes resection of hemi-liver, caudate lobe, node dissection, securing safe biliary margin and biliary-enteric anastomosis. Obtaining safe margin from portal vein and hepatic artery is necessary because tumor can spread through horizontal and perpendicular direction as well. Furthermore, duct-to-enteric anastomosis after resection may be needed. Accordingly, laparoscopic procedures for hilar cholangiocarcinoma are the most technically demanding and surgeon should be proficient for performing LLR, laparoscopic lymph node dissection, hepaticojejunostomy. Recent studies reported successful cases for hilar cholangiocarcinoma. In contrast, other study reported worse perioperative outcome after laparoscopic biliary-enteric anastomosis with LLR compared with LLR only. Follow-up studies on long-term outcomes are necessary.

\section{ROLE OF MINIMAL INVASIVE SURGERY IN THE TREATMENT OF IHCC}

Recent advances in surgical techniques and equipment made minimally invasive hepatectomy being more popular to treat liver tumors (2-6). Minimal invasive hepatectomy has been known to be associated with better short-term outcomes (7) including pain, hospital stay and blood loss and similar long-term outcomes compared to open surgery (8).

However, reports about LLR for IHCC are very rare (9-12), maybe due to technical difficulty of major liver resection, necessity of laparoscopic lymph node dissection, and bile duct resection (13). Recent retrospective case series showed that LLR for IHCC showed better short-term outcomes, including intraoperative blood loss, hospital stay, and complications compared to open surgery. The 5-year overall and disease-free survival rates were similar between LLR and open resection in selected patients in experienced centers (9). A study by Lee, et al, also showed similar oncologic outcomes in selected patients with IHCC (11). Moreover, there are a report that LLR is safe, and have good long-term outcomes in selected patients even with large or multiple IHCCS (14).
A significant difference between IHCC and HCC is lymphatic spread in IHCC. Lymph node metastases are frequently found in patients with IHCC according to macroscopic type: $<20 \%$ in intraductal growth type compared with $80 \%$ in the mass forming and periductal infiltrative type (15). Many reports including recent expert consensus statement recommended lymph node dissection (16), although it is still controversial (17-20).

Area of lymph node dissection may vary according to the origin of primary tumor on the liver, for the right liver on the retropancreatic lymph nodes and for left liver on cardiac portion and the lesser curvature of the stomach (21). For IHCC with nodal involvement or intrahepatic metastasis, surgery alone may be not enough for prolonging survival, and further studies should be performed to clarify the indications for surgery in this group of IHCC $(22,23)$.

\section{ROLE OF MINIMAL INVASIVE SURGERY IN THE TREATMENT OF HILAR CHOLANGIO- CARCINOMA}

Hilar cholangiocarcinoma, also known as a Klatskin tumor, differs from other IHCC in terms of the treatment method and prognosis. The 5 year survival rate has been reported to range from $15 \%$ to $35 \%$, even after curative resection. Curative resection is often difficult because of invasion into adjacent important vessels and longitudinal extension along the bile duct in the submucosal layer. Only radical resection can give a chance of long term survival outcome in Klatskin tumor. The surgical procedure consists of extended hemihepatectomy, including caudate lobectomy, and regional lymphadenectomy. Because of the complexity of the surgical procedures, there have been very few reports on laparoscopic resection of hilar cholangiocarcinoma (24).

Recent reports have described the feasibility and safety of minimal invasive surgery for hilar cholangiocarcinoma (24-28). There are several difficulties in performing LLR for hilar cholangiocarcinoma. Major LLR combined with caudate lobectomy is usually needed. The caudate lobe ducts join the left and right hepatic ducts near their confluence. The close anatomic relationship of these ducts to caudate lobe increase the possibility of tumor invasion into the caudate lobe. Caudate lobectomy requires meticulous dissection, which can be accomplished relatively well using laparoscopic procedures (29). Laparoscopic hilar lymphadenectomy and bilioenteric reconstruction are also necessary procedures. Nevertheless, despite the perceived difficulty associated with laparoscopic proce- 
dures, several studies have demonstrated the safety of each component of laparoscopic resection of hilar cholangiocarcinoma, and further experience of performing this procedure will provide further support for its use (24). In this types of surgery, robotic assisted surgery will be beneficial.

\section{CONCLUSIONS}

Surgery still confers the only treatment option to increase long-term survival in patients with IHCC. LLR for IHCC or hilar cholangiocarcinoma have many controversies, but tailored, individualized treatment with a multidisciplinary approach could improve quality of life and patient survival.

\section{Conflict of interest}

The authors declare that there are no conflicts of interest.

\section{REFERENCE}

1. Cho JY, Han HS, Wakabayashi G, Soubrane O, Geller D, O'Rourke N, et al. Practical guidelines for performing laparoscopic liver resection based on the second international laparoscopic liver consensus conference. Surg Oncol. 2018;27(1):A5-A9.

2. Guro H, Cho JY, Han HS, Yoon YS, Choi Y, Periyasamy M. Current status of laparoscopic liver resection for hepatocellular carcinoma. Clin Mol Hepatol. 2016;22(2):212-8.

3. Komatsu S, Brustia R, Goumard C, Perdigao F, Soubrane 0, Scatton 0 . Laparoscopic versus open major hepatectomy for hepatocellular carcinoma: a matched pair analysis. Surg Endosc. 2016;30(5): 1965-74.

4. Takahara T, Wakabayashi G, Beppu T, Aihara A, Hasegawa K, Gotohda N, et al. Long-term and perioperative outcomes of laparoscopic versus open liver resection for hepatocellular carcinoma with propensity score matching: a multi-institutional Japanese study. J Hepatobiliary Pancreat Sci. 2015;22(10):721-7.

5 Kwon Y, Han HS, Yoon YS, Cho JY. Are large hepatocellular carcinomas still a contraindication for laparoscopic liver resection? J Laparoendosc Adv Surg Tech A. 2015;25(2):98-102.

6. Yoon YS, Han HS, Cho JY, Yoon CJ, Kim JH. Laparoscopic approach for treatment of multiple hepatocellular carcinomas. Surg Endosc. 2012;26(11):3133-40.

7. Nguyen KT, Gamblin TC, Geller DA. World review of laparoscopic liver resection-2,804 patients. Annals of surgery. 2009;250(5) :831-41.

8. Wakabayashi G, Cherqui D, Geller DA, Buell JF, Kaneko H, Han HS et al. Recommendations for laparoscopic liver resection: a report from the second international consensus conference held in Morioka. Ann Surg. 2015;261(4):619-29.

9. Uy BJ, Han HS, Yoon YS, Cho JY. Laparoscopic liver resection for intrahepatic cholangiocarcinoma. J Laparoendosc Adv Surg Tech A. 2015;25(4):272-7.

10. Ratti F, Cipriani F, Ariotti R, Gagliano A, Paganelli M, Catena M, et al. Safety and feasibility of laparoscopic liver resection with associated lymphadenectomy for intrahepatic cholangiocarcinoma: a propensity score-based case-matched analysis from a single institution. Surg Endosc. 2016;30(5):1999-2010.
11. Lee W, Park JH, Kim JY, Kwag SJ, Park T, Jeong SH, et al. Comparison of perioperative and oncologic outcomes between open and laparoscopic liver resection for intrahepatic cholangiocarcinoma. Surg Endosc. 2016;30(11):4835-4840.

12. Abu Hilal M, Badran A, Di Fabio F, Pearce NW. Pure laparoscopic en bloc left hemihepatectomy and caudate lobe resection in patients with intrahepatic cholangiocarcinoma. J Laparoendosc Adv Surg Tech A. 2011;21(9):845-9.

13. Cho JY, Han HS, Yoon YS, Ahn KS, Kim YH, Lee KH. Laparoscopic approach for suspected early-stage gallbladder carcinoma. Arch Surg. 2010 Feb;145(2):128-33.

14. Wei F, Lu C, Cai L, Yu H, Liang X, Cai X. Can laparoscopic liver resection provide a favorable option for patients with large or multiple intrahepatic cholangiocarcinomas? Surg Endosc. 2017; 31(9):3646-3655.

15. Ohtsuka M, Ito H, Kimura F, Shimizu H, Togawa A, Yoshidome H, et al. Results of surgical treatment for intrahepatic cholangiocarcinoma and clinicopathological factors influencing survival. $\mathrm{Br} \mathrm{J}$ Surg. 2002;89(12):1525-31.

16. Weber SM, Ribero D, O'Reilly EM, Kokudo N, Miyazaki M, Pawlik TM. Intrahepatic cholangiocarcinoma: expert consensus statement. HPB (Oxford). 2015;17(8):669-80.

17. Uenishi T, Kubo S, Yamazaki O, Yamada T, Sasaki Y, Nagano H, et al. Indications for surgical treatment of intrahepatic cholangiocarcinoma with lymph node metastases. J Hepatobiliary Pancreat Surg. 2008;15(4):417-22.

18. Okabayashi T, Yamamoto J, Kosuge T, Shimada K, Yamasaki S, Takayama $\mathrm{T}$, et al. A new staging system for mass-forming intrahepatic cholangiocarcinoma: analysis of preoperative and postoperative variables. Cancer. 2001;92(9):2374-83.

19. Choi SB, Kim KS, Choi JY, Park SW, Choi JS, Lee WJ, et al. The prognosis and survival outcome of intrahepatic cholangiocarcinoma following surgical resection: association of lymph node metastasis and lymph node dissection with survival. Ann Surg Oncol. 2009; 16(11):3048-56.

20. de Jong MC, Nathan H, Sotiropoulos GC, Paul A, Alexandrescu S, Marques $\mathrm{H}$, et al. Intrahepatic cholangiocarcinoma: an international multi-institutional analysis of prognostic factors and lymph node assessment. J Clin Oncol. 2011; 29(23):3140-5.

21. Edge SB. AJCC Cancer Staging Manual. New York, NY: Springer; 2009.

22. Weber SM, Jarnagin WR, Klimstra D, DeMatteo RP, Fong $\mathrm{Y}$, Blumgart LH. Intrahepatic cholangiocarcinoma: resectability, recurrence pattern, and outcomes. Journal of the American College of Surgeons. 2001;193(4):384-91.

23. Shimada K, Sano T, Nara S, Esaki M, Sakamoto Y, Kosuge T, et al. Therapeutic value of lymph node dissection during hepatectomy in patients with intrahepatic cholangiocellular carcinoma with negative lymph node involvement. Surgery. 2009;145(4):411-6.

24. Lee W, Han HS, Yoon YS, Cho JY, Choi Y, Shin HK, et al. Laparoscopic resection of hilar cholangiocarcinoma. Ann Surg Treat Res. 2015;89(4):228-32.

25. Machado MA, Makdissi FF, Surjan RC, Mochizuki M. Laparoscopic resection of hilar cholangiocarcinoma. J Laparoendosc Adv Surg Tech A. 2012;22(10):954-6.

26. Cho A, Yamamoto H, Kainuma O, Muto Y, Yanagibashi H, Tonooka T, et al. Laparoscopy in the management of hilar cholangiocarcinoma. World J Gastroenterol. 2014; 20(41):15153-7.

27. Yu H, Wu SD, Chen DX, Zhu G. Laparoscopic resection of Bismuth type I and II hilar cholangiocarcinoma: an audit of 14 cases from two institutions. Dig Surg. 2011:28(1):44-9.

28. Gumbs AA, Jarufe N, Gayet B. Minimally invasive approaches to extrapancreatic cholangiocarcinoma. Surg Endosc. 2013;27(2) :406-14.

29. Ho KM, Han HS, Yoon YS, Cho JY, Choi YR, Jang JS, et al. Laparoscopic Total Caudate Lobectomy for Hepatocellular Carcinoma. J Laparoendosc Adv Surg Tech A. 2017;27(10): 1074-1078. 